\title{
Night feeding in lactating sows is an essential management approach to decrease the detrimental impacts of heat stress
}

\author{
YoHan Choi ${ }^{1}$, Joseph Moturi ${ }^{2}$, Abdolreza Hosseindoust ${ }^{2}$, MinJu Kim², KwangYeol Kim², JunHyung Lee ${ }^{2}$, \\ ChangHyun Song ${ }^{2}$, YoungHwa Kim ${ }^{1}$ and ByungJo Chae ${ }^{2^{*}}$
}

${ }^{1}$ Swine Division, National Institute of Animal Science, Rural Development Administration, Cheonan 31000, Korea

${ }^{2}$ College of Animal Life Sciences, Kangwon National University, Chuncheon 24341, Korea

\begin{abstract}
The present study investigated the litter performance of multiparous sows had different feeding frequencies during summer season. A total of 60 crossbred multiparous sows was allotted to one of two treatments based on body weight (BW) according to a completely randomized design. Two different feeding frequencies based on NRC (National Research Council) were applied as conventional feeding (T1; $2 \mathrm{~kg}$ per meal at 06:00, 11:00, and 17:00) and night feeding (T2; $1.5 \mathrm{~kg}$ per meal at 06:00, 11:00, 17:00, and $2 \mathrm{~kg}$ at 22:00). Sows in T2 treatment had lower $(p<0.05)$ BW changes during lactation. The backfat thickness change of sows was decreased in T2 treatment during lactation $(p<0.05)$. The daily feed intake differed significantly between T1 and T2 with increased feed intake of the T2 group at $5.47 \mathrm{~kg} / \mathrm{d}$ to $5.14 \mathrm{~kg} / \mathrm{d}$ in the T1 group $(p<0.05)$. There was a significant difference in total weight of weaned piglets between T1 $(70.50 \mathrm{~kg})$ and T2 $(74.34 \mathrm{~kg})$. A greater total litter weight gain was observed in sows in T2 treatment. Night feeding is suggested for lactating sows with significant beneficial effects on litter growth during summer season.
\end{abstract}

Keywords: Backfat, Feeding, Heat stress, Lactating sows, Litter performance

\section{Background}

Summer heat impacts negatively on livestock production inflicting heavy losses on farmers. The elevated temperatures during the summer detrimentally affect lactating sows performance, particularly voluntary feed intake [1]. The decline in voluntary feed intake during heat stress has been associated with the negative effects on production parameters [2]. In addition, high ambient temperature has been demonstrated to have a pronounced negative impact on milk production of lactating sows, which is correlated with reduced body weight (BW) of piglets at weaning [3,4]. Studies have shown that milk production is basically dependent on feed consumption to provide the required nutrients for lactogenesis [5]. Not only feed intake depression, but also the reduction in the amount blood flow to the mammary glands are responsible for less delivered nutrients for milk synthesis resulting in reduced milk yield and decreased piglet growth [6,7]. Lactating sows mobilize a high rate of body reserves to compensate the adverse effects of heat stress on milk yield reduction, which lead to increased backfat and BW loss [6,8]. Moreover, the prolonged weaning-to-estrus intervals and increased incidences of anestrus in lactating sows are associated with heat stress [9].

There are various strategies that are aimed at reducing the negative impacts of high ambient temperature on feed intake 
during summer in intensive rearing systems such as redesigning the feeding program and changing the feeding time to the cooler phases of the day or at night $[2,10,11]$. Night feeding allows the heat of digestion to be produced during the cooler hours when it's more easily dissipated. Previous study showed that the voluntary feed intake increased in cooler hours of the day in sows exposed to high ambient temperature [3]. This facilitates increased uptake of nutrients to maintain milk production and inhibit mobilization of sow's body reserves, which lead to prevent negative impacts in sow's reproduction and piglets growth. The current study objectives were to determine the effect of extended feeding into the night in improving feed intake in lactating sows during summer season. We hypothesized that night feeding, when ambient temperatures are low will stimulate increased feed intake, thereby ameliorating the negative impacts of heat stress on sow's production and reproductive abilities.

\section{Materials and Methods}

A total of 60 crossbred sows (Yorkshire $\times$ Landrace; average initial BW, $245.2 \pm 17.2 \mathrm{~kg}$ ) was allotted to one of two treatments on the basis of performance and parity (13 second parity, 23 third parity, 17 forth parity, and 7 fifth parity). Sows were divided into two groups, day feeding (2 $\mathrm{kg}$ per meal at 06:00,11:00, and 17:00), and night feeding $(1.5 \mathrm{~kg}$ per meal at 06:00, 11:00, 17:00, and 2 $\mathrm{kg}$ at 22:00). All sows used in the present study were artificially inseminated 2 times after the onset of oestrus, and pregnancy was detected and confirmed at $\mathrm{d} 30$ post-breeding using a Pharvision B-mode ultrasound machine (AV 2,100 V; Ambisea Tech. Corp., Shenzhen, China). Sow backfat thickness (BFT) at the 10th rib, 6.5 $\mathrm{cm}$ from one side of the backbone was measured at farrowing, and weaning ( $\mathrm{d} 25$ of lactation) by using a medical imaging ultrasound (Loveland, CO; USA). Changes in BFT of sows during lactation were measured by calculating the difference between BFT at $\mathrm{d} 1$ of lactation and BFT at weaning (d 25 of lactation). Standard litter traits such as the total number born and born alive, BW (kg) at birth, and weaning, growth rate $(\mathrm{kg} / \mathrm{d})$, and average daily gain $(\mathrm{g} /$ piglets) were recorded individually. Feed intake ( $\mathrm{kg} / \mathrm{d}$ ) of each sow and weaning-to-oestrus interval (d) were also recorded. All the sows were fed a common diet according to the National Research Council [12] requirements for lactation (Table 1). Cross-fostering was performed within 1 day of parturition. From 1 day after weaning, oestrus detection was performed twice-daily (08:00 and $16: 30 \mathrm{~h}$ ) for $10 \mathrm{~min}$ by boar exposure. The daily rectal temperature was recorded at 15:00 $\mathrm{h}$ during the study. The minimum, average, and maximum ambient temperatures observed in the conventional farrowing rooms $\left(25.8 \pm 1.4^{\circ} \mathrm{C}, 28.6 \pm 1.9^{\circ} \mathrm{C}\right.$, and $31.1 \pm 2.4^{\circ} \mathrm{C}$ respectively).
Table 1. Formula and chemical composition of lactation sow diets (asfed basis)

\begin{tabular}{|c|c|}
\hline Item & Value \\
\hline Ingredients (g/100 g DM) & 100.00 \\
\hline Corn & 62.50 \\
\hline Soybean meal & 28.60 \\
\hline Animal fat & 2.63 \\
\hline Molasses & 2.00 \\
\hline Three calcium phosphate & 1.54 \\
\hline Limestone & 1.48 \\
\hline Salt & 0.50 \\
\hline Choline chloride (50\%) & 0.05 \\
\hline L-Lysine·HCl (78\%) & 0.05 \\
\hline DL-Methionine (99.8\%) & - \\
\hline L-Threonine (98.5\%) & 0.03 \\
\hline L-Tryptophan (10\%) & 0.18 \\
\hline L-Valine $(98.5 \%)$ & 0.09 \\
\hline Vitamin premix ${ }^{1)}$ & 0.15 \\
\hline Mineral premix ${ }^{2)}$ & 0.15 \\
\hline Phytase & 0.05 \\
\hline Metabolizable energy (MJ/kg) & 13.81 \\
\hline Crude protein & 17.80 \\
\hline Calcium & 0.88 \\
\hline Availablephosphorus & 0.44 \\
\hline SID. Arg & 1.03 \\
\hline SID. His & 0.41 \\
\hline SID. lle & 0.62 \\
\hline SID. Leu & 1.36 \\
\hline SID. Lys & 0.88 \\
\hline SID. Met & 0.23 \\
\hline SID. Met + Cys & 0.48 \\
\hline SID. Thr & 0.56 \\
\hline SID. Trp & 0.18 \\
\hline SID. Val & 0.75 \\
\hline
\end{tabular}

${ }^{11}$ Supplied per kilogram of vitamin premix: vitamin $A, 12,000,000 \mathrm{IU}$; vitamin $D_{3}$, 2,400,000 IU; vitamin E, 132,000 IU; vitamin $K_{3}, 1,500 \mathrm{mg}$; vitamin $B_{1}, 3,000 \mathrm{mg}$; vitamin $B_{2}, 11,250 \mathrm{mg}$; vitamin $B_{6}, 3,000 \mathrm{mg}$; vitamin $B_{12}, 45 \mathrm{mg}$; pantothenic acid, $36,000 \mathrm{mg}$; niacin, 30,000 mg; biotin, $600 \mathrm{mg}$; folic acid, 4,000 mg.

${ }^{2)}$ Supplied per kilogram of mineral premix: $\mathrm{Fe}, 80,000 \mathrm{mg}$; Co, $170 \mathrm{mg}$; Cu, 8,500 mg; Mn, 25,000 mg; Zn, 95,000 mg; I, 140 mg; Se, 150 mg.

On day 1 (post farrowing), and day 25 (weaning, after piglet removal) of lactation, $10-\mathrm{mL}$ blood samples were collected by ear vein catheter before the morning feeding at 6:00 using a disposable vacutainer tube containing sodium heparin as an anticoagulant (Becton Dickinson, Franklin, NJ). Serum automatic biochemical analyzer (Fuji Dri-chem 3500i, Japan) was applied to measure concentrations of blood urea nitrogen, glucose, and triglyceride. Insulin, follicle stimulating hormone (FSH), luteinizing hormone $(\mathrm{LH})$, and cortisol were measured by using kits (Endocrine Tech- 
nologies Inc., USA) and their concentrations were determined in duplicate by ELISA using Biolog MicroStation system. The minimal detectable concentrations of insulin, $\mathrm{LH}$ and FSH were $0.5,0.1$, and $0.5 \mathrm{ng} / \mathrm{mL}$, respectively. After centrifugation (3,000 $\times \mathrm{g}$ for 20 min), plasma samples were separated and stored at $-20{ }^{\circ} \mathrm{C}$ and later analyzed for blood parameters.

Colostrum and milk were collected $(30 \mathrm{~mL})$ just after the birth of the first piglet and 10 days after farrowing respectively. The samples were for protein, fat, and lactose composition. Nutritional composition (fat, protein, and lactose content) was analyzed estimated by Milko-Scan 133B (Type 10911) within 24 hours. IgG content $(\mathrm{mg} / \mathrm{mL})$ was measured by Procine IgG ELISA Kit (E101-104, Belthyl Lab., USA).

Data generated in the present experiment were analyzed by the SAS statistical package (SAS 9.1, SAS Institute, Cary, NC, USA). The main effects of feeding types were determined by the Student's $t$-test. Initial BW of sows was considered as a covariate. A $p$-values $\leq 0.05$ were considered statistically significant.

\section{Results}

There was no difference in rectal temperature of sows between the treatments (data not shown), and the average rectal temperature was $39.3^{\circ} \mathrm{C}$.

\section{Feed intake and sow performance}

The effect of feeding frequency on feed intake and sow performance is shown in Table 2. Body weight of sows was not different among the treatments. However, sows in T2 treatment had lower $(p<0.05)$ BW change during lactation. The BFT change of sows were decreased in T2 treatment during lactation $(p<0.05)$. The daily feed intake differed significantly between T1 and T2 treatments with increased feed intake of the T2 treatment at $5.47 \mathrm{~kg} / \mathrm{d}$ compared with $5.14 \mathrm{~kg} / \mathrm{d}$ in the T1 treatment $(p<0.05)$. However, the weaning to estrus interval was not affected.

\section{Litter performance}

The effect of frequency of feeding on litter performance of lactating sows during summer season is shown in Table 3. There were no significant effects between $\mathrm{T} 1$ and $\mathrm{T} 2$ on the initial litter size, number of piglets weaned, survivability, and initial litter weight. There was a significant difference $(p<0.01)$ between T1 $(70.50 \mathrm{~kg})$ and T2 $(74.34 \mathrm{~kg})$ in total weight of weaned piglets. However, the average daily gain of piglets was not affected by the treatments.

\section{Blood metabolites}

The blood concentration of urea nitrogen, glucose, triglyceride, and creatinine were not affected (Table 4).

\section{Hormone profiles}

There were no significant effects of feeding time on FSH, LH, cortisol, and insulin level of serum (Table 5).

\section{Milk and colostrum composition}

There were no treatment effects on total solid, protein, fat, and lactose content of colostrum (Table 6). The milk content of total solid, fat, and lactose was not differed between the treatments, however, there was a tendency $(p=0.085)$ for higher milk protein in sows in T2 treatment.

\section{Discussion}

Both BW change and backfat change were decreased in the night fed group. Research has shown that sows under heat stress experienced a 13\% decline in feed intake and a significant BW loss during lactation [8]. This BW change can be attributed to

Table 2. Effects of feeding frequency on reproductive performance of lactating sows during summer

\begin{tabular}{|c|c|c|c|c|}
\hline Item & T1 & T2 & SEM & $p$-value \\
\hline Parity & 3.80 & 3.77 & 0.27 & 0.932 \\
\hline \multicolumn{5}{|l|}{ Sow body weight (kg) } \\
\hline Lactation (dL) & 248.19 & 242.44 & 4.20 & 0.337 \\
\hline Weaning & 225.01 & 224.04 & 3.75 & 0.876 \\
\hline Change, - & 23.18 & 18.40 & 1.10 & 0.003 \\
\hline \multicolumn{5}{|l|}{ Sow backfat thickness (mm) } \\
\hline Lactation (dL) & 20.63 & 20.22 & 0.51 & 0.360 \\
\hline Weanling & 15.82 & 16.33 & 0.39 & 0.281 \\
\hline Change, - & 4.82 & 3.88 & 0.22 & 0.002 \\
\hline Daily feed intake $(\mathrm{kg} / \mathrm{d})$ & 5.14 & 5.47 & 0.11 & 0.018 \\
\hline Weaning to estrus interval (d) & 4.97 & 4.57 & 0.24 & 0.253 \\
\hline
\end{tabular}

T1, 3 feeding time per day (06:00, 11:00, and 17:00); T2, 4 feeding time per day (06:00, 11:00, 17:00, and 22:00); SEM, standard error of means. 
Table 3. Effects of feeding frequency on litter size and piglet performance of lactating sows during summer

\begin{tabular}{|c|c|c|c|c|}
\hline Item & T1 & T2 & SEM & $p$-value \\
\hline \multicolumn{5}{|l|}{ Litter size } \\
\hline Initial litter size & 10.53 & 10.67 & 0.20 & 0.645 \\
\hline Piglets weaned & 9.97 & 10.20 & 0.14 & 0.255 \\
\hline Survivability (\%) & 95.11 & 95.93 & 1.01 & 0.565 \\
\hline \multicolumn{5}{|l|}{ Litter performance } \\
\hline Initial litter weight (kg/sow) & 15.92 & 15.64 & 0.28 & 0.309 \\
\hline Initial litter (kg/pig) & 1.52 & 1.47 & 0.09 & 0.799 \\
\hline Piglets weaned & 70.50 & 74.34 & 0.87 & 0.003 \\
\hline Piglets weaned (kg/pig) & 7.12 & 7.31 & 0.13 & 0.287 \\
\hline Total weight gain (kg/sow) & 54.58 & 58.70 & 0.85 & 0.001 \\
\hline Average daily gain (g/pig) & 223.79 & 233.70 & 4.49 & 0.126 \\
\hline
\end{tabular}

T1, 3 feeding time per day (06:00, 11:00, and 17:00); T2, 4 feeding time per day (06:00, 11:00, 17:00, and 22:00); SEM, standard error of means.

Table 4. Effects of feeding frequency on blood metabolites of lactating sows during summer

\begin{tabular}{|c|c|c|c|c|}
\hline Item & T1 & T2 & SEM & $p$-value \\
\hline \multicolumn{5}{|l|}{ Post farrowing (mg/dL) } \\
\hline Blood urea nitrogen & 16.40 & 16.29 & 0.52 & 0.879 \\
\hline Glucose & 91.76 & 91.46 & 4.08 & 0.960 \\
\hline Triglyceride & 53.07 & 52.39 & 2.02 & 0.816 \\
\hline Creatinine & 2.05 & 2.03 & 0.04 & 0.769 \\
\hline \multicolumn{5}{|l|}{ Weanling (mg/dL) } \\
\hline Blood urea nitrogen & 16.84 & 17.84 & 0.43 & 0.130 \\
\hline Glucose & 93.04 & 90.61 & 2.97 & 0.574 \\
\hline Triglyceride & 24.87 & 28.08 & 1.48 & 0.155 \\
\hline Creatinine & 1.94 & 1.82 & 0.05 & 0.102 \\
\hline
\end{tabular}

T1, 3 feeding time per day (06:00, 11:00, and 17:00); T2, 4 feeding time per day (06:00, 11:00, 17:00, and 22:00); SEM, standard error of means.

Table 5. Effects of feeding frequency on hormone profiles of lactating sows during summer

\begin{tabular}{|c|c|c|c|c|}
\hline Item & T1 & T2 & SEM & $p$-value \\
\hline \multicolumn{5}{|l|}{$\mathrm{FSH}(\mathrm{ng} / \mathrm{mL})$} \\
\hline Post farrowing & 2.07 & 2.05 & 0.03 & 0.627 \\
\hline Weanling & 3.03 & 3.10 & 0.02 & 0.103 \\
\hline \multicolumn{5}{|l|}{$\mathrm{LH}(\mathrm{ng} / \mathrm{mL})$} \\
\hline Post farrowing & 0.52 & 0.50 & 0.02 & 0.408 \\
\hline Weanling & 0.62 & 0.66 & 0.02 & 0.156 \\
\hline \multicolumn{5}{|l|}{ Cortisol (ng/mL) } \\
\hline Post farrowing & 6.53 & 6.36 & 0.20 & 0.541 \\
\hline Weanling & 4.72 & 4.21 & 0.27 & 0.205 \\
\hline \multicolumn{5}{|l|}{ Insulin ( $\mu \mathrm{IU} / \mathrm{mL})$} \\
\hline Post farrowing & 20.67 & 20.42 & 0.40 & 0.664 \\
\hline Weanling & 17.47 & 18.15 & 0.29 & 0.127 \\
\hline
\end{tabular}

T1, 3 feeding time per day (06:00, 11:00, and 17:00); T2, 4 feeding time per day (06:00, 11:00, 17:00, and 22:00); SEM, standard error of means; FSH, follicle stimulating hormone; LH, luteinizing hormone. 
Table 6. Effects of feeding frequency on colostrum and milk composition of lactating sows during summer

\begin{tabular}{|c|c|c|c|c|}
\hline Item & T1 & T2 & SEM & $p$-value \\
\hline \multicolumn{5}{|l|}{ Colostrum (\%) } \\
\hline Total solid & 22.14 & 22.35 & 0.57 & 0.801 \\
\hline Protein & 15.38 & 15.52 & 0.37 & 0.805 \\
\hline Fat & 5.53 & 5.66 & 0.17 & 0.598 \\
\hline Lactose & 3.63 & 3.71 & 0.14 & 0.672 \\
\hline \multicolumn{5}{|l|}{ Milk (\%) } \\
\hline Total solid & 17.98 & 18.57 & 0.79 & 0.612 \\
\hline Protein & 5.60 & 6.01 & 0.16 & 0.085 \\
\hline Fat & 7.10 & 7.63 & 0.23 & 0.129 \\
\hline Lactose & 5.26 & 5.62 & 0.18 & 0.208 \\
\hline
\end{tabular}

T1, 3 feeding time per day (06:00, 11:00, and 17:00); T2, 4 feeding time per day (06:00, 11:00, 17:00, and 22:00); SEM, standard error of means.

mobilization of body lipids and protein reserves to cater for the increased energy demands of lactation and the net energy deficit due to reduced feed intake. Low nutrient intake in heat-stressed pigs fully explain the reduced gross/live carcass weight, which is in agreement with previous studies on pig [2] and cattle [13]. In another study, the reduced feed intake resulted in declining backfat deposition during heat stress [7]. This is thought to be an adaptive mechanism to allow for increased dissipation of heat through the skin in hot weather as fats insulate the body against heat loss which is deleterious under conditions of heat stress [3,6].

Heat stress impacts negatively on sows' production and reproductive performance, particularly during the lactation phase of production. Basically, lactating sows are in a negative energy balance due to the increased energy demand and inability to consume enough feed to maintain the high energy requirements [14]. This reduced appetite during heat stress is presumably a strategy to reduce metabolic heat production avoiding a further increase in body temperature. In a previous study it was demonstrated that feed intake of sows decreases up to $50 \%$ during heat stress [1]. Furthermore, a decrease of feed intake in sows is thought to be a physiological mechanism aimed at controlling heat increment.

Various feeding strategies have been designed to ameliorate the effects of heat stress during summer season such as feeding in the cooler hours of the day. In the present study, night feeding improved feed intake in lactating sows during summer season. Our study showed a significant increase in feed intake in the night fed group. It has been suggested that feed intake tends to be increased with a decline in ambient temperature during early morning and late evening periods [3]. In a study on multiparous large white lactating sows, it was confirmed that feed intake at nighttime was higher than daytime [15]. It is hypothesized that night feeding allows the heat of digestion to be shifted to the cooler periods of the day when it is more easily dissipated. Therefore, a reduction in intensity of heat stress may positively affect feed intake.
The total weight gain of piglets was improved by the pattern of feeding in the current study. This may have been due to increased feed intake. Higher feed intake may be accompanied with higher nutrient availability for milk production, and possibly affecting piglet growth. As heat stress increases at daytime, the sows suffer more from depressed appetite, and further decrease may occur in the amount of available nutrient and energy for milk production. Similar results were also obtained by Silva et al. [15], where sows consumed less feed, produced less milk, and showed a lower litter growth during the hot season as compared to sows in the thermoneutral season. Reduced total weight gain in piglets from the daytime fed group may also be attributed to suckling behavior of these piglets. Due to reduced milk production, the piglets tend to have a more suckling frequency per day with an increased suckling interval than piglets from the night fed sows [6].

The results from our study did not show any significant difference in blood glucose between the daytime fed and the night fed groups at post farrowing and weaning despite the night fed group having a higher feed intake, whereas it has been reported that heat stress causes a reduction in blood sugar concentration in pigs because of the decline in feed consumption [14]. In agreement, Farmer et al. [10] found no change in glucose concentration in sows that were exposed to heat stress. Changes in blood metabolites are important indicators during heat stress, however, the only differences were noted for a tendency in blood triglycerides with a numerically higher concentration in the night fed group, and a tendency for higher blood creatinine concentration in the daytime fed group, which may be attributed to the increased mobilization of muscle.

In the current study, no significant differences were obtained in total solid, protein, fat and lactose of colostrum and milk, although there was a tendency for the concentration of milk protein. Sows in the night fed group showed a numerically higher milk protein, likely due to higher feed and amino acid intake. Milk yield was 
not measured in the present study, however, it has been shown that sows with higher feed intake have greater milk production capacity and greater litter weight gain in comparison to sows with low feed intake [16].

\section{Conclusion}

In conclusion, the present study shows that night feeding at lactation period decreases BW loss and increases feed intake of sows subjected to hot ambient temperatures, resulting a greater litter weight at weaning time.

\section{Competing interests}

No potential conflict of interest relevant to this article was reported.

\section{Funding sources}

Not applicable.

\section{Acknowledgements}

This work was carried out with the support of Cooperative Research Program for Agriculture Science and Technology Development (Project No. 01160302), Rural Development Administration, Korea.

\section{Availability of data and material}

Upon reasonable request, the datasets of this study can be available from the corresponding author.

\section{Authors' contributions}

Conceptualization: Chae BJ, Kim YH.

Data curation: Lee JH, Moturi J.

Formal analysis: Kim MJ, Song CH.

Methodology: Kim KY, Choi YH.

Software: Hosseindoust A.

Validation: Lee JH, Moturi J.

Investigation: Kim KY, Moturi J, Song CH.

Writing - original draft: Lee JH.

Writing - review \& editing: Choi YH, Moturi J, Hosseindoust A, Kim MJ, Kim KY, Lee JH, Song CH, Kim YH, Chae BJ.

\section{Ethics approval and consent to participate}

The project underwent proper ethical standards and the experiments (KW-170519-1) were approved by the Institutional Animal Care and Use Committee of Kangwon National University, Chuncheon, Korea.

\section{ORCID}

YoHan Choi
Joseph Moturi

https://orcid.org/0000-0002-0626-0255

Abdolreza Hosseindoust https://orcid.org/0000-0001-9191-0613

MinJu Kim

KwangYeol Kim

JunHyung Lee

ChangHyun Song

YoungHwa Kim

ByungJo Chae

https://orcid.org/0000-0001-6950-0458

https://orcid.org/0000-0002-3723-2978

https://orcid.org/0000-0002-7937-7817

https://orcid.org/0000-0002-0138-6924

https://orcid.org/0000-0002-9850-8894

https://orcid.org/0000-0002-8570-698X

\section{References}

1. Renaudeau D, Gourdine JL, St-Pierre NR. A meta-analysis of the effects of high ambient temperature on growth performance of growing-finishing pigs. J Anim Sci. 2011;89:222030.

2. Choi Y, Hosseindoust A, Kim J, Lee S, Kim M, Kumar A, et al. An overview of hourly rhythm of demand-feeding pattern by a controlled feeding system on productive performance of lactating sows during summer. Ital J Anim Sci. 2018;17:1001-9.

3. Renaudeau D, Collin A, Yahav S, de Basilio V, Gourdine JL, Collier RJ. Adaptation to hot climate and strategies to alleviate heat stress in livestock production. Animal. 2012;6:707-28.

4. Quiniou N, Noblet J. Influence of high ambient temperatures on performance of multiparous lactating sows. J Anim Sci. 1999;77:2124-34.

5. Kim K, Choi Y, Hosseindoust A, Kim M, Hwang S, Bu M, et al. Evaluation of high nutrient diets and additional dextrose on reproductive performance and litter performance of heatstressed lactating sows. Animal Sci J. 2019;90:1212-9.

6. Renaudeau D, Noblet J. Effects of exposure to high ambient temperature and dietary protein level on sow milk production and performance of piglets.J Anim Sci. 2001;79:1540-8.

7. King'ori AM. Sow lactation: colostrum and milk yield: a review.J Anim Sci Adv. 2012;2:525-33.

8. McGlone JJ, Stansbury WF, Tribble LF, Morrow JL. Photoperiod and heat stress influence on lactating sow performance and photoperiod effects on nursery pig performance. J Anim Sci. 1988;66:1915-9.

9. Choi Y, Hosseindoust A, Shim Y, Kim M, Kumar A, Oh S, et al. Evaluation of high nutrient diets on litter performance of heat-stressed lactating sows. Asian-Australas J Anim Sci. 2017;30:1598-604.

10. Farmer C, Knight C, Flint D. Mammary gland involution and endocrine status in sows: effects of weaning age and lactation heat stress. Can J Anim Sci. 2007;87:35-43.

11. Hong JS, Jin SS, Jung SW, Fang LH, Kim YY. Evaluation of dry feeding and liquid feeding to lactating sows under high temperature environment.J Anim Sci Technol. 2016;58:36. 
12. NRC [National Research Council]. Nutrient requirements of swine. 11th ed. Washington, DC: National Academy Press; 2012.p.420.

13. Nejad JG, Lohakare JD, West JW, Kim BW, Lee BH, Sung $\mathrm{KI}$. Effects of water restriction following feeding on nutrient digestibilities, milk yield and composition and blood hormones in lactating Holstein cows under heat stress conditions. Ital J Anim Sci. 2015;14:3952.

14. Pearce SC, Gabler NK, Ross JW, Escobar J, Patience JF, Rhoads RP, et al. The effects of heat stress and plane of nutrition on metabolism in growing pigs. J Anim Sci. 2013;91:2108-18.

15. Silva BAN, Oliveira RFM, Donzele JL, Fernandes HC, Lima AL, Renaudeau D, et al. Effect of floor cooling and dietary amino acids content on performance and behaviour of lactating primiparous sows during summer. Livest Sci. 2009;120:2534.

16. Strathe AV, Bruun TS, Hansen CF. Sows with high milk production had both a high feed intake and high body mobilization. Animal. 2017;11:1913-21. 